\title{
Research on the Influencing Factors of "Scale Veins" of Single Point Incremental Forming Workpieces Surface
}

\author{
Shi Pengtao ${ }^{*}, 1,2$, Li Yan $^{1}$, Yang Mingshun ${ }^{1}$ and Yao Zimeng ${ }^{1}$ \\ ${ }^{1}$ School of Mechanical and Precision Instrument Engineering, Xi'an University of Technology, 710048, Xi'an, China \\ ${ }^{2}$ College of Mechanical \& Electrical Engineering, Shaanxi University of Science \& Technology, 710021, Xi'an, China
}

\begin{abstract}
To furthermore optimize the machining parameters and improve the surface quality of the workpieces manufactured by single point incremental forming method, the formation mechanism of the sacle veins on the metal incremental froming workpieces was studied through experiment method. The influence principle of the spindle speed, the feed speed and the material of tip of tools on the length of scale veins was obtained through analyzing the experimental results and building the mathematical model among the length of scale veins were feed speed and spindle speed through measuring the roughness of surfaces and observing the appearance of the forming workpieces. The experimental results showed that, the spindle speed, the feed speed and the material of tool tips have a significant effect on the scale veins formation on the surface of forming workpieces. Therefore, an appropriate group of spindle speed and feed speed can reduce the effect of scale veins on the roughness of single point incremental forming workpieces and furthermore improve the surface quality of forming workpieces.
\end{abstract}

Keywords: Feed speed, Incremental forming, Scale veins, Spindle speed, Surface quality, Surface roughness.

\section{INTRODUCTION}

In the 1980s, Matsuhara Shio, Japanese scholar, proposed an incremental forming technology-a sheet metal mouldless flexible manufacturing technology. In this technology, depending on the hierarchical manufacturing concept, the three-dimensional entity is cut into slices hierarchically along the contour line to form a series of two-dimensional layers; each layer is formed in accordance with a certain track and is processed to form the final shape [1-4]. This technology is independent of special moulds, and is high in flexibility and repeatability, so that the development period of metal sheet metal parts is shortened, the huge mould manufacturing costs are saved, and the application prospect is extensive [5-8].

Currently, the study on the surface quality of formed workpieces is the important direction of the study of the incremental forming technology. Wu Yan et al. from Nanjing Aeronautics and Astronautics University analyzed the change rule of parts in different forming angles via test comparison [9]. Jeswiet et al. from Queen's University in Canada established quantitative relation between part shapes and increment step length [10]. Durante et al. from University of Naples Federico in Italy derived relation between peak valley height and the radius and increment step length of forming tool [11]. Song Xiucheng et al. from Shanghai Jiaotong University drew the mechanism of action and influence degree of each factor of influence of the surface quality of incremental forming parts [12]. The study

*Address correspondence to this author at the School of Mechanical and Precision Instrument Engineering, Xi'an University of Technology, 710048, Xi’an, China; E-mail: shipengtao@sust.edu.cn of the above persons is mainly focused on the influence of interlayer residual wave height on surface quality during the processing of incremental forming, but they were less focused on the study on the surface quality in each layer.

In this article, the forming mechanism of scale veins in each layer is analyzed via the experiment and the influence rule of various process parameters on scale veins is studied to provide theoretical basis for reducing the influence of scale veins and further improving the surface quality of formed workpieces.

\section{EXPERIMENT PRINCIPLE}

Under the further observation of the surfaces of sheet metal single-point incremental forming workpieces, we can find that the surfaces of formed workpieces have two veins affecting their surface quality. One is the transverse vein formed by residual wave between every two layers, and the other is scaly vein in each layer (hereinafter referred to as scale figure), as shown in the Fig. (1). The main influence factors of the first vein include interlayer spacing, the radius of tool head, forming angle, etc., and the influence of the first vein on the surface quality can be reduced by adjusting these parameters. When the influence of the first vein on the surface quality is reduced to a certain degree, scale veins in the layers are the major reason affecting the surface quality. In this article, the feed speed, rotating speed of spindle, spindle material, etc. are changed in the experiment process to obtain the workpiece surfaces with different surface quality. Surface roughness $\mathrm{Rz}$ value is measured by using the surface roughometer. At the same time, surface morphology is observed by using the stereoscopic microscope, and the formation mechanism of scale veins and the influence rule of 
scale veins on surface quality are explored via the analysis on numerical values and surface morphology.

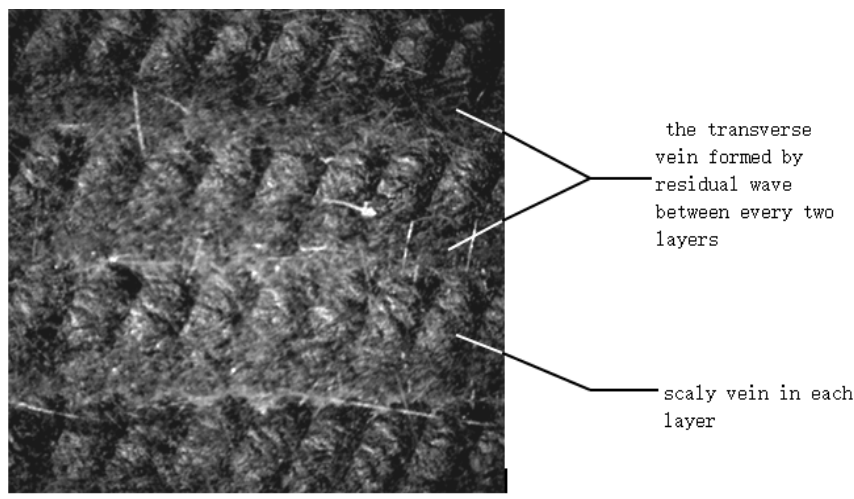

Fig. (1). Two kinds of workpieces surface vein.

\section{EXPERIMENT SETTINGS}

\subsection{Experiment Equipment and Material}

In this experiment, the CY-VMC850 machining center is used as the main equipment of incremental forming. The clamp is fixed on the machining center by utilizing the flat tongs, as shown in the Fig. (2). The head of forming tool is the cylinder with diameter of $\varphi 10$, the end is in the hemispherical shape, and surface is polished. In order to reduce the abrasion of the tool head and prolong the service life of the tool head, the tool head is lubricated by using Kunlun Tianrun KR8 lubricating oil. 2A112 plate of 150 $\mathrm{mm} \times 150 \mathrm{~mm} \times 1 \mathrm{~mm}$ is used as the experiment material. After machining, surface roughness Rz value is measured by using the Time TR200 surface roughometer, surface morphology of sample parts is observed by using the PXS5$\mathrm{T}$ stereoscopic microscope, and the cycle length of veins is measured.

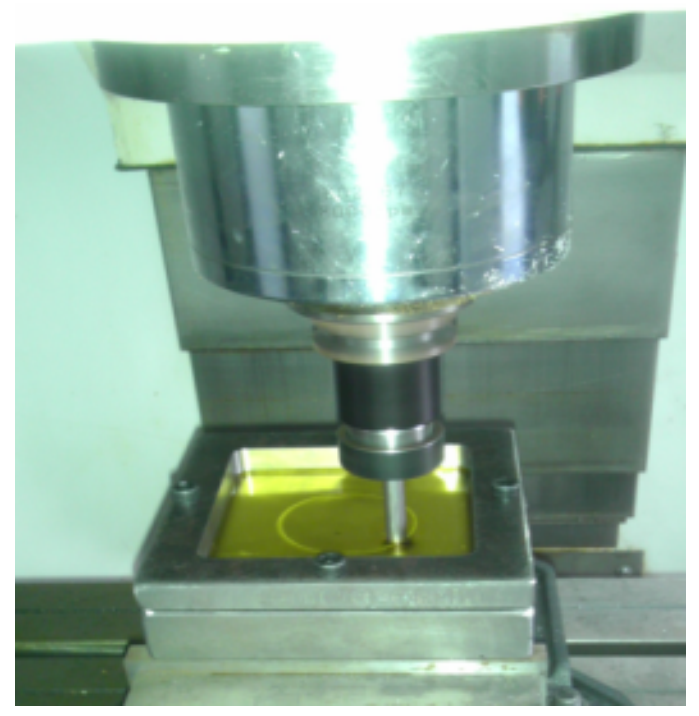

Fig. (2). Single point incremental forming process.

\subsection{Parameter Setting}

In this experiment, the inverted square bench is used as the experimental model, and is machined along the path of contour line, as shown in the Fig. (3).

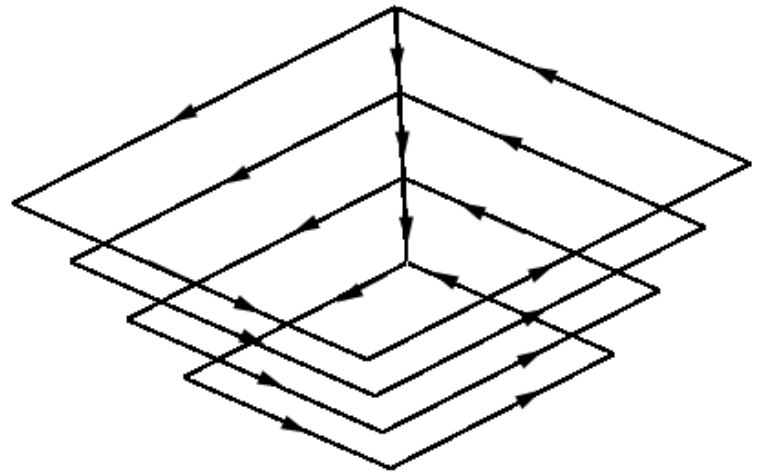

Fig. (3). The process path.

\subsubsection{Forming Angle}

As the incremental forming process of the sheet metal is similar to forming by spinning, we can establish the shearing deformation mechanism in the incremental forming process by taking example of the deformation mechanism of forming by spinning [13-16]. The shearing deformation mechanism considers that metal basically makes shear flow along the axial direction of workpieces in the incremental forming process [17, 18], and after forming, the change in the thickness of sheet metal conforms to the cosine rule, as shown in the Fig. (4).

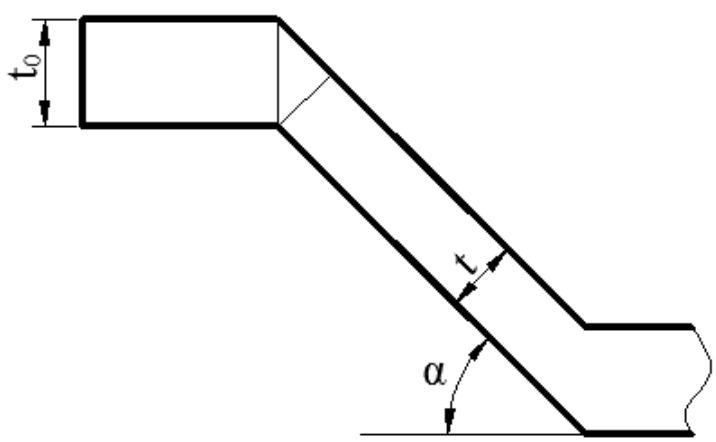

Fig. (4). The thinning rate.

From the Fig. (4),

$t=t_{0} \cos \alpha$

where,

$t_{0}$-Original thickness of sheet metal

$t$-Thickness of formed sheet metal

$\alpha$-Forming angle

Thinning rate:

$\Psi_{t}=\left[\left(t_{0}-t\right) / t_{0}\right] \times 100 \%$

The formula (1) is substituted to obtain

$\Psi_{t}=(1-\cos \alpha) \times 100 \%$

From the experiment, in order to avoid the cracks of 2Al12 sheet metal of $1 \mathrm{~mm}$, the maximum thinning rate of the sheet metal shall not exceed 69.9\% [11], and it is substituted into the formula (3) to obtain the forming angle $\alpha=72.5^{\circ}$, thus, the forming angle $\alpha$ shall be less than $72.5^{\circ}$, and in this experiment, $\alpha=45^{\circ}$ to avoid cracks and even breakage. 


\subsubsection{Increment Step Length}

In this article, the influence of scale veins in each layer on surface quality is studied, thus, a certain increment step length shall be selected to reduce the influence of interlayer residual wave height on surface quality, so that scale veins are the main factor affecting the surface quality. The relation $[19,20]$ between interlayer residual wave height and increment step length is shown in the Fig. (5).

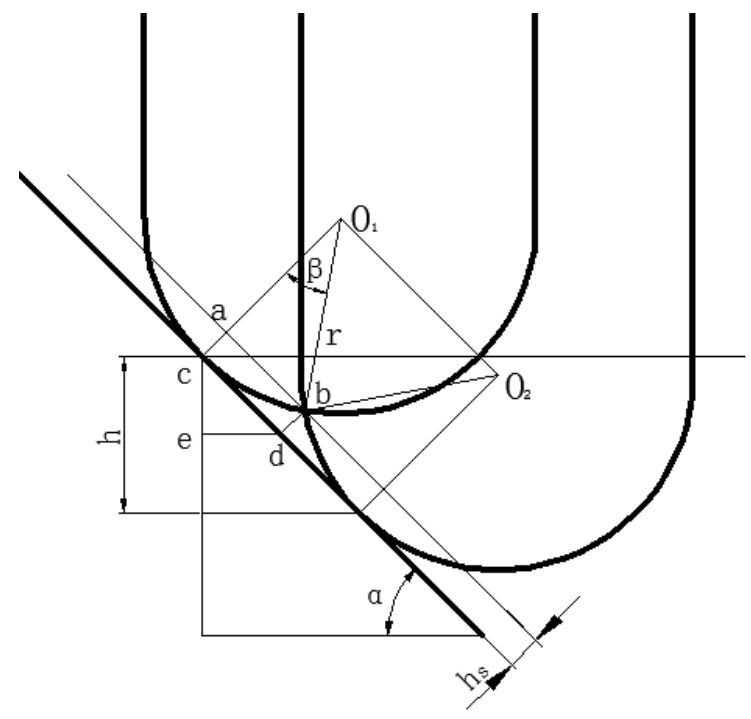

Fig. (5). Inter layer residual wave height.

From the Fig (5),

$\sin \beta=\frac{a b}{r}=\frac{c d}{r}=\frac{(h / 2) / \sin \alpha}{r}=\frac{h}{2 r \sin \alpha}$

where,

$h$-Increment step length

$r$-Radius of tool head

$\alpha$-Forming angle

Table 1. The Rz value under different spindle speed. $\cos \beta=\frac{r-h_{s}}{r}$

where,

$\mathrm{h}_{\mathrm{s}}$-Interlayer residual wave height

Combine (4) and (5) to obtain

$h_{s}=r-\left(r^{2}-\frac{h^{2}}{4 \sin ^{2} \alpha}\right)^{\frac{1}{2}}$

As increment step length is $0.5 \mathrm{~mm}, \mathrm{~h}_{\mathrm{s}}=12.5 \mu \mathrm{m}$, in the actual machining process, due to the influence of the vibration, friction, shearing, etc. of tool head, surface roughness $\mathrm{Rz}$ is $3.632 \mu \mathrm{m}$ [21], which is close to the surface roughness $\mathrm{Rz}$ of sheet metal without machining, and at the moment, scale veins are the main factor affecting surface quality.

\subsubsection{Setting of Other Parameters}

In order to study the scale veins better, we hope to obtain the distinct appearance of the scale veins. Therefore, in this experiment, the rotating speed of spindle is 50 to $1000 \mathrm{r} / \mathrm{min}$, and the feed speed is 100 to $1000 \mathrm{~mm} / \mathrm{min}$. The scale veins are distinct to facilitate the study.

\section{EXPERIMENT}

\subsection{Experiment of the Influence of the Rotating Speed of Spindle on the Scale Veins on the Formed Surface}

\subsubsection{Experiment Scheme Design and Parameter Setting}

In this experiment, the tool head is made of hard alloy material, the feed speed of spindle is $300 \mathrm{~mm} / \mathrm{min}$, and the machining path is in the counterclockwise direction. The spindle rotates at the speed of 50 to $950 \mathrm{r} / \mathrm{min}$ in the clockwise direction, and is tested at intervals of $100 \mathrm{r} / \mathrm{min}$. After the experiment is finished, 6 different positions are selected randomly on each machined surface. Rz is measured by using the surface roughometer along the direction which

\begin{tabular}{|c|c|c|c|c|c|c|c|}
\hline \multirow{2}{*}{ Rotation Speed n $\left(\mathbf{r} \cdot \mathbf{m i n}^{-1}\right)$} & \multicolumn{4}{|c|}{ Rz $(\boldsymbol{\mu m})$} & \multicolumn{2}{|c|}{$\mathbf{5}$} & \multicolumn{2}{|c|}{$\mathbf{6}$} \\
\cline { 2 - 8 } & $\mathbf{1}$ & $\mathbf{2}$ & $\mathbf{3}$ & $\mathbf{4}$ & \multicolumn{2}{|c|}{ Mean Value } \\
\hline \hline 50 & 12.050 & 12.87 & 9.019 & 11.360 & 12.920 & 12.890 & 11.852 \\
\hline 150 & 4.168 & 5.312 & 6.996 & 5.917 & 4.553 & 4.718 & 5.277 \\
\hline 250 & 3.150 & 5.581 & 3.880 & 4.625 & 4.986 & 4.607 & 4.472 \\
\hline 350 & 4.319 & 4.391 & 4.121 & 5.279 & 4.795 & 5.338 & 4.707 \\
\hline 450 & 4.772 & 4.007 & 4.121 & 5.015 & 4.385 & 4.007 & 4.385 \\
\hline 550 & 4.883 & 3.305 & 5.153 & 4.930 & 3.461 & 3.270 & 4.167 \\
\hline 650 & 2.390 & 4.050 & 3.431 & 6.505 & 3.684 & 4.223 & 4.047 \\
\hline 750 & 2.698 & 4.123 & 2.815 & 2.346 & 7.346 & 4.405 & 3.956 \\
\hline 850 & 2.935 & 2.581 & 7.891 & 3.962 & 2.742 & 3.197 & 3.885 \\
\hline 950 & 3.126 & 3.525 & 3.038 & 3.170 & 4.258 & 5.903 & 3.837 \\
\hline
\end{tabular}


(a) $\mathrm{S}=150 \mathrm{r} / \mathrm{min}$ surface morphology of sample

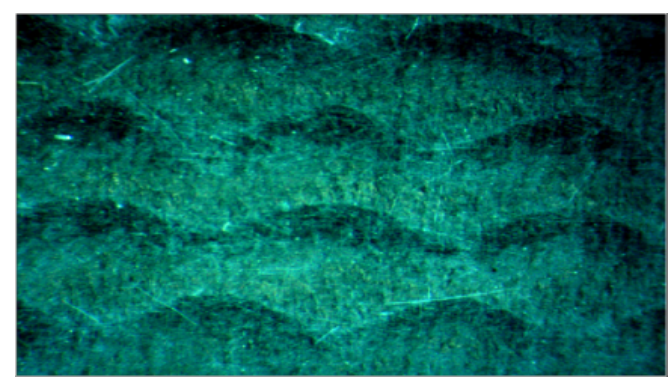

(c) $\mathrm{S}=650 \mathrm{r} / \mathrm{min}$ surface morphology of sample

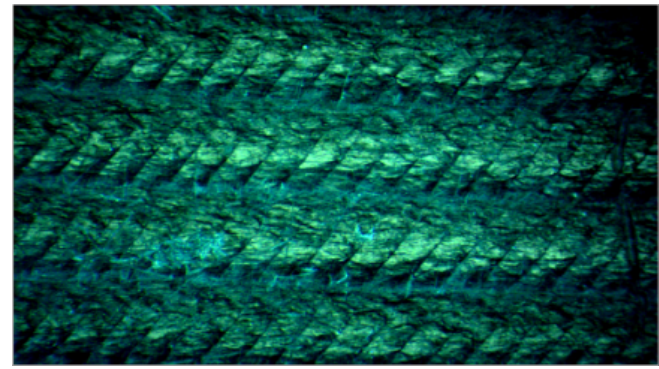

(b) $\mathrm{S}=350 \mathrm{r} / \mathrm{min}$ surface morphology of sample

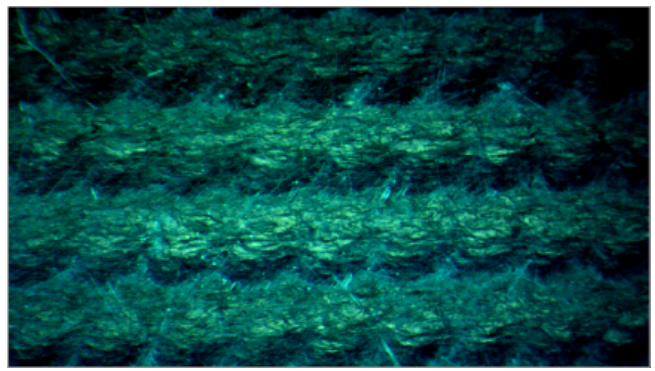

(d) $\mathrm{S}=950 \mathrm{r} / \mathrm{min}$ surface morphology of sample

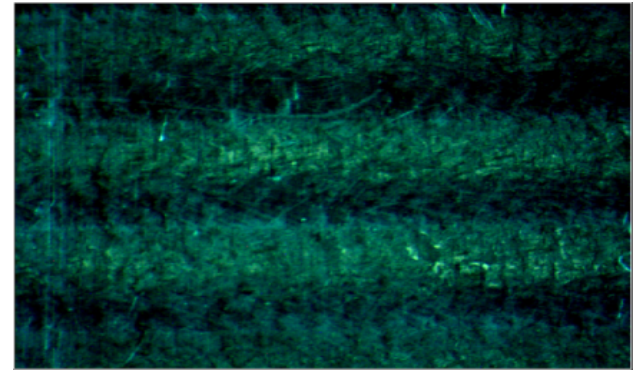

Fig. (6). The surface morphology of the Sample under different spindle speed.

is parallel to the contour line, its arithmetic mean value is valued, and at the same time, the surface morphology of sample parts is observed by using the stereoscopic microscope.

\subsubsection{Experimental Result}

The measuring results of surface roughness $\mathrm{Rz}$ at different rotating speeds are shown in the Table 1. Data in the Table $\mathbf{1}$ is subjected to Kruskal-Wallis inspection of multiple independent samples; significance is $p=0.002<$

0.05 , indicating that the influence of the rotating speed of spindle on roughness $\mathrm{Rz}$ is significant within $95 \%$

confidence interval. And the higher the rotating speed of spindle is, the smaller the surface roughness $\mathrm{Rz}$ is .

The surface of the sample is observed by using the stereoscopic microscope, as shown in the Fig. (6). The scale veins on the surface are changed periodically, when the rotating speed is low, the cycle length of surface veins is large, and the wavy veins appear on the surface, as shown in the Fig. (6a); and when the rotating speed is high, the cycle length is reduced, the scaly veins appear on the surface, as shown in the Fig. (6b-d). The wavy veins and the scaly veins are essentially the same veins, the forming principle is the same, and they are in different shapes due to different cycle lengths.

\subsection{Experiment of the Influence of the Feed Speed on the Scale Veins on the Formed Surface}

\subsubsection{Experiment Scheme Design and Parameter Setting}

In this experiment, the tool head is made of hard alloy material, the feed speed of spindle is $300 \mathrm{r} / \mathrm{min}$, and the machining path is in the counterclockwise direction, as shown in the Fig. (4). The spindle rotates in the clockwise direction, the feed speed is 100 to $1000 \mathrm{~mm} / \mathrm{min}$, and is tested at intervals of $100 \mathrm{r} / \mathrm{min}$. After the experiment is finished, 6 different positions are selected randomly on each machined surface, $\mathrm{Rz}$ is measured by using the surface roughometer along the direction which is parallel to the contour line, its arithmetic mean value is valued, and at the same time, the surface morphology of sample parts is observed by using the stereoscopic microscope.

\subsubsection{Experimental Results}

The measuring results of surface roughness $\mathrm{Rz}$ at different feed speeds are shown in the Table 2.

Data is subjected to Kruskal-Wallis inspection of multiple independent samples; significance is $\mathrm{p}=0.008<$ 0.05 , indicating that the influence of the feed speed on roughness $\mathrm{Rz}$ is significant within $95 \%$ confidence interval, and the feed speed is higher, the surface roughness $\mathrm{Rz}$ is larger, and the scale veins are more obvious. The feed speed is lower, the surface roughness $\mathrm{Rz}$ is smaller, and the scale veins are more unapparent.

The surface of the sample is observed by using the microscope, as shown in the Fig. (7). Under the overall consideration of $\mathrm{Rz}$ in the Table 2 , when the feed speed is higher, the cycle length of surface veins is larger, and the surface roughness $\mathrm{Rz}$ is larger, and when the feed speed is lower, the cycle length of surface veins is smaller, and the surface roughness $\mathrm{Rz}$ is smaller.

\subsection{Influence of Tool Head Made of Different Materials on Scale Veins}

\subsubsection{Experiment Scheme Design and Parameter Setting}

In this experiment, the rotating speed of spindle is 300 $\mathrm{r} / \mathrm{min}$, and the machining path is in the counterclockwise direction, as shown in the Fig. (4). The spindle rotates in the 
Table 2. The Rz value under different feed speed.

\begin{tabular}{|c|c|c|c|c|c|c|c|}
\hline Feed Speed (mm/min) & 1 & 2 & 3 & 4 & 5 & 6 & Mean Value \\
\hline 200 & 4.516 & 4.185 & 4.278 & 4.947 & 4.625 & 4.425 & 4.496 \\
\hline 300 & 4.615 & 5.124 & 3.614 & 4.347 & 5.014 & 4.527 & 4.540 \\
\hline 500 & 4.214 & 4.694 & 5.102 & 5.514 & 6.105 & 4.572 & 5.034 \\
\hline 600 & 5.307 & 4.117 & 4.758 & 6.589 & 5.279 & 5.381 & 5.239 \\
\hline 700 & 4.532 & 5.369 & 5.854 & 6.598 & 5.125 & 5.146 & 5.437 \\
\hline 800 & 5.329 & 4.598 & 5.867 & 6.658 & 6.215 & 5.486 & 5.692 \\
\hline
\end{tabular}

(a) $\mathrm{F}=200 \mathrm{~mm} / \mathrm{min}$ sample photograph

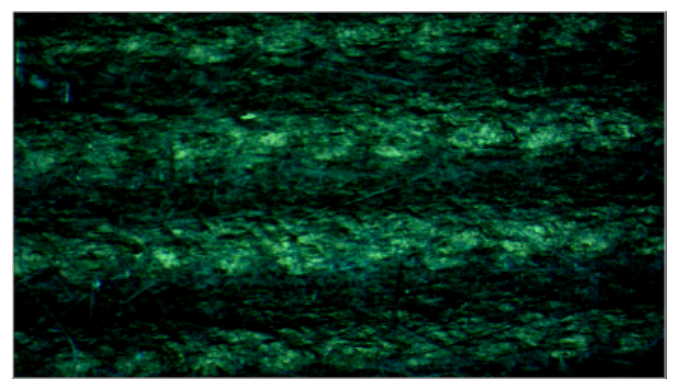

(c) $\mathrm{F}=400 \mathrm{~mm} / \mathrm{min}$ sample photograph

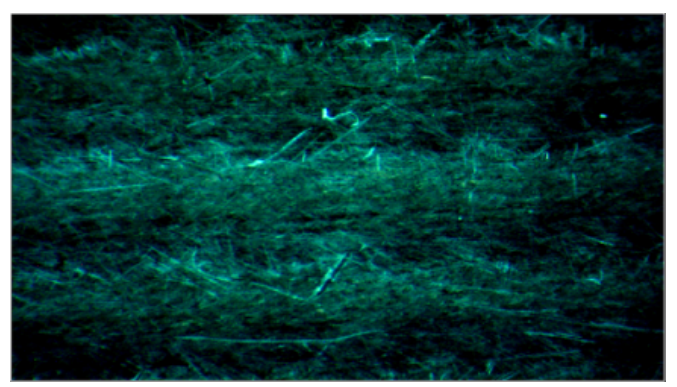

(b) $\mathrm{F}=300 \mathrm{~mm} / \mathrm{min}$ sample photograph

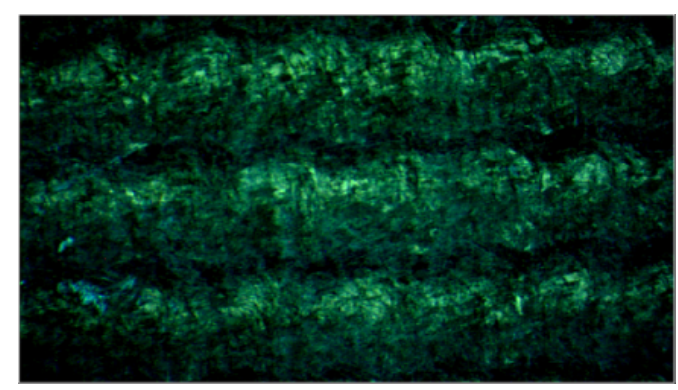

(d) $\mathrm{F}=500 \mathrm{~mm} / \mathrm{min}$ sample photograph

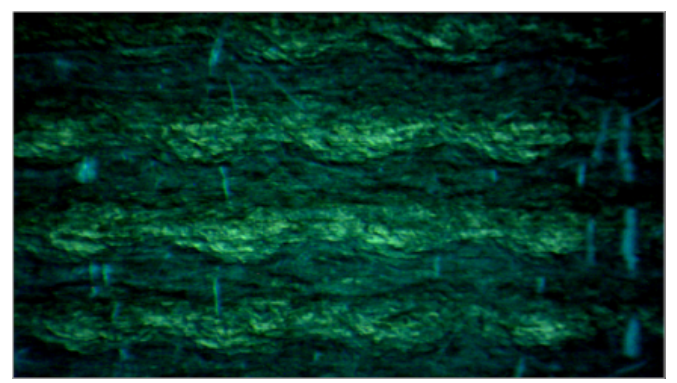

Fig. (7). The surface morphology of the Sample under different feed speed.

clockwise direction, the feed speed is $300 \mathrm{~mm} / \mathrm{min}$, and Q235, 40Cr, 06Cr19Ni10 and 45 are used as the materials of the tool head respectively to be tested. After the experiment is finished, 6 different positions are selected randomly on each workpiece. $\mathrm{Rz}$ is measured by using the surface roughometer along the direction which is parallel to the contour line, and its arithmetic mean value is valued, and at the same time, the surface morphology of sample parts is observed by using the stereoscopic microscope.

\subsubsection{Experimental Results}

Sample parts are machined by using the tool head made of different materials, and the results of the measured surface roughness $\mathrm{Rz}$ are shown in the Table 3. Data is subjected to Kruskal-Wallis inspection of multiple independent samples; significance is $p=0.005<0.05$, indicating that the influence of the hardness of the tool head on roughness $\mathrm{Rz}$ is significant within $95 \%$ confidence interval, and when the hardness is larger, the surface roughness $\mathrm{Rz}$ is smaller; and when the hardness is smaller, the surface roughness $\mathrm{Rz}$ is larger. The photographs of the scale veins under the stereoscopic microscope are shown in the Fig. (8), when the tool heads are made of different materials, the cycle lengths of the machined surface veins are basically the same, the material hardness is larger, surface veins are more unapparent, the surface roughness $\mathrm{Rz}$ is smaller; and when the material hardness is smaller, surface veins are more obvious, and the surface roughness $\mathrm{Rz}$ is larger. 
Table 3. The Rz value under different material of tool tips.

\begin{tabular}{|c|c|c|c|c|c|c|c|c|}
\hline \multirow{2}{*}{ Material of Tool Tips } & \multirow{2}{*}{ HRC } & \multicolumn{7}{|c|}{$\operatorname{Rc}(\mu \mathrm{m})$} \\
\hline & & 1 & 2 & 3 & 4 & 5 & 6 & Mean Value \\
\hline Q235 & 30 & 6.532 & 7.802 & 7.679 & 6.723 & 7.019 & 7.861 & 7.269 \\
\hline $40 \mathrm{Gr}$ & 34 & 7.335 & 6.893 & 6.717 & 8.614 & 5.045 & 7.597 & 7.034 \\
\hline 06Cr19Ni10 & 40 & 6.661 & 7.341 & 6.805 & 7.015 & 5.675 & 6.631 & 6.688 \\
\hline 45 & 43 & 6.487 & 6.871 & 4.663 & 5.177 & 7.989 & 5.637 & 6.137 \\
\hline Hard alloy & 69 & 4.299 & 5.047 & 4.373 & 4.138 & 4.171 & 5.287 & 4.553 \\
\hline
\end{tabular}

(a) Sample photograph of tool tip made of Q235 material

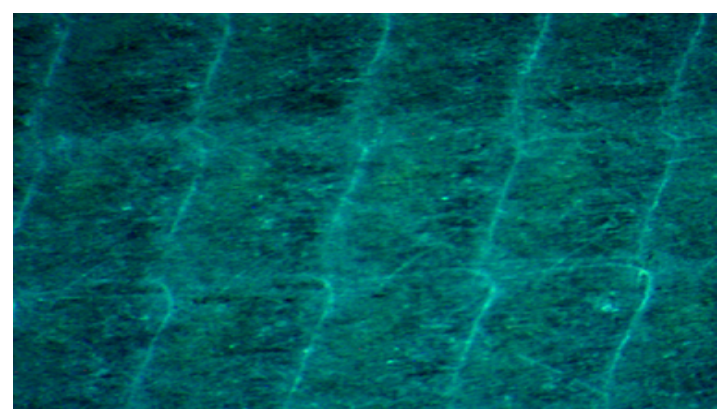

(c) Sample photograph of tool tip made of $40 \mathrm{Gr}$ materiall

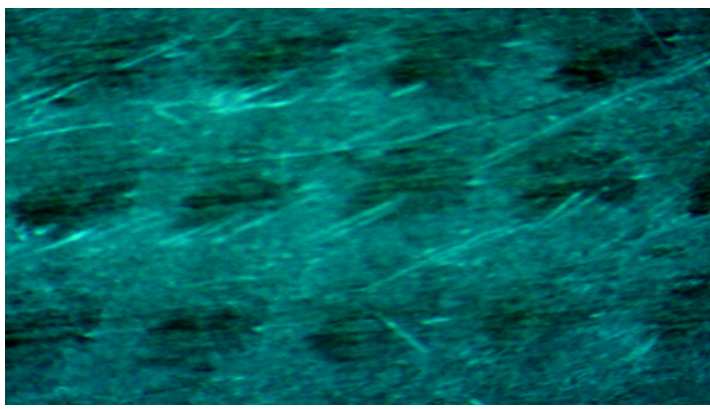

(b) Sample photograph of tool tip made of 45 material

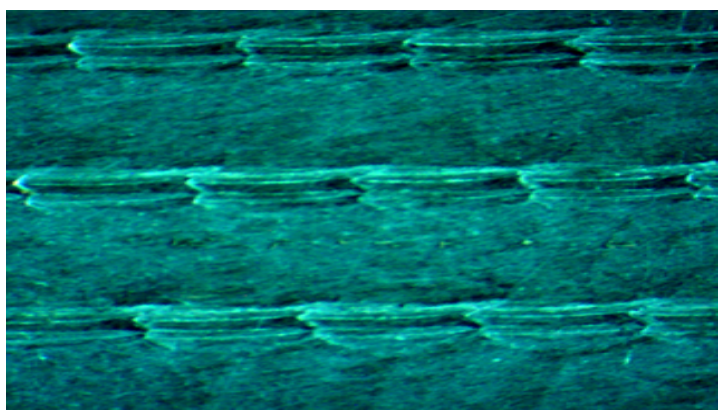

(d) Sample photograph of tool tip made of 06Cr19Ni10 material

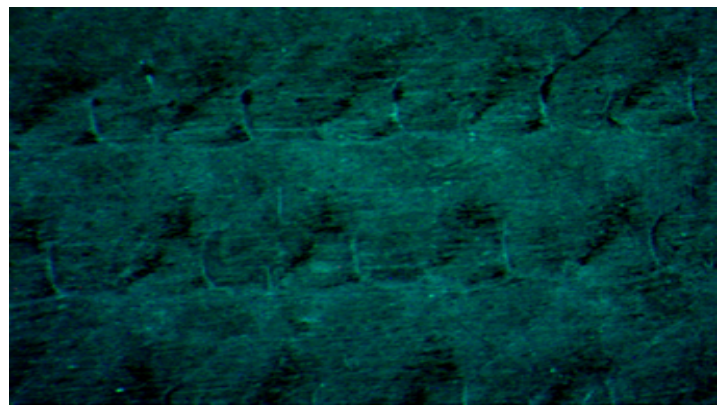

Fig. (8). The surface morphology of the Sample under different material of tool tips.

\section{ANALYSIS OF EXPERIMENTAL RESULTS}

\subsection{Analysis of Formation Reason of Scale Veins}

As shown in the Fig. (9), during incremental forming, tool tips may be bent and deformed under the resistance in the reverse direction in the machining process. Simultaneously, the spindle rotates, so that the size and direction of the force of tool tips are changed continuously. The size and direction of the extrusion force of the formed surface of sheet metal are also changed periodically with the rotation of tool tips under the retroaction of force, so that the surfaces of the formed workpieces are extruded to form periodic veins, namely scale veins.

\subsection{Cycle Length of Scale Veins}

From the above analysis, the formed surface of sheet metal is subjected to the extrusion force which is changed periodically in size and direction. The periodic change of the extrusion force occurs as the tool tips rotate by a circle to form the scale veins on the formed surface of sheet metal. Therefore, cycle length is

$L=v t$

where,

$v$-Movement speed of spindle $(\mathrm{mm} / \mathrm{s})$

$t$-Time required by every cycle (s)

$v=F / 60$

where,

$F$-Feed speed (mm/min)

$t=1 \times 60 / \mathrm{S}$

where,

$S$-Rotating speed of spindle (r/min)

Combine the formulas (7), (8) and (9),

$L=F / S$ 


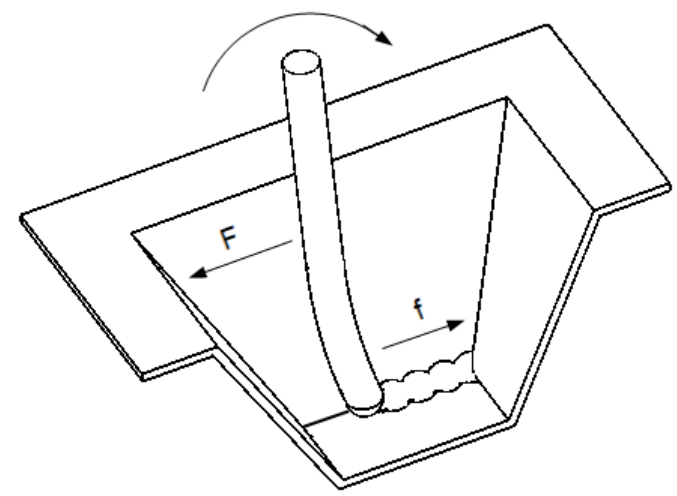

Fig. (9). The formation reason of scale veins.

From the formula (10), in the case of regular rotating speed $\mathrm{S}$, the feed speed $\mathrm{F}$ is higher, and the cycle length of the scale veins is larger. In the case of regular feed speed F, the rotating speed $\mathrm{S}$ of spindle is larger, and the cycle length of the scale veins is smaller. The cycle lengths of the above experiments are measured respectively, as shown in the Fig. (10), and values are consistent with the results derived from the above formulas.

(a) Relation diagram of cycle length and rotating speed of spindle

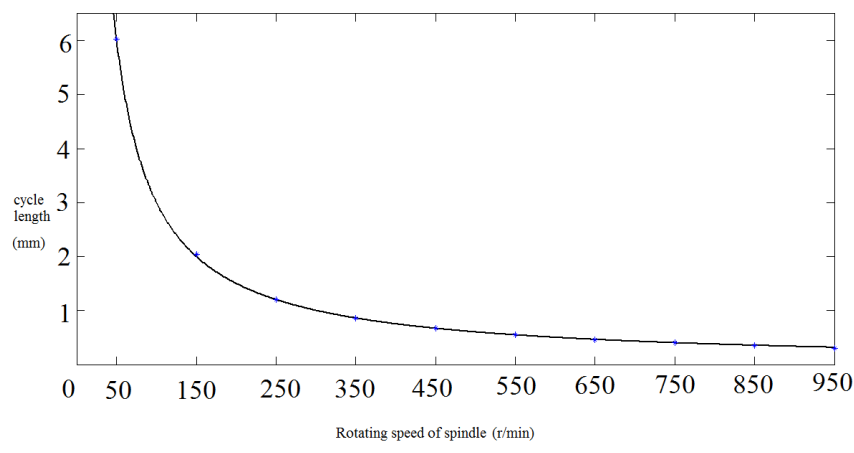

(b) Relation diagram of cycle length and feed speed

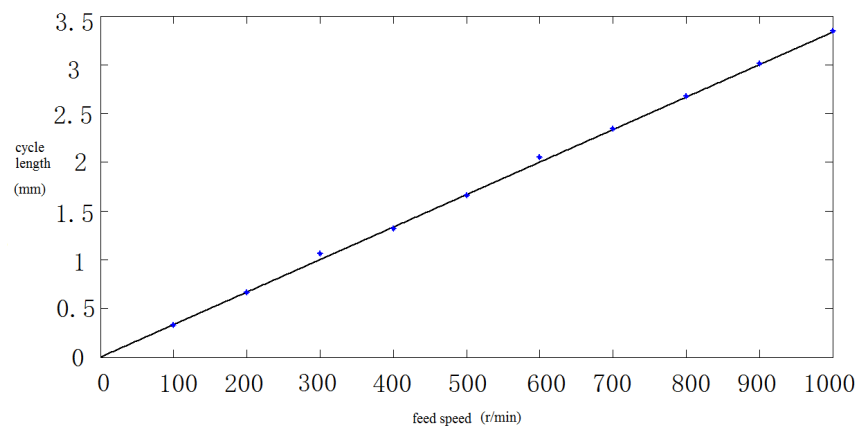

(c) Relation diagram of cycle length and different materials

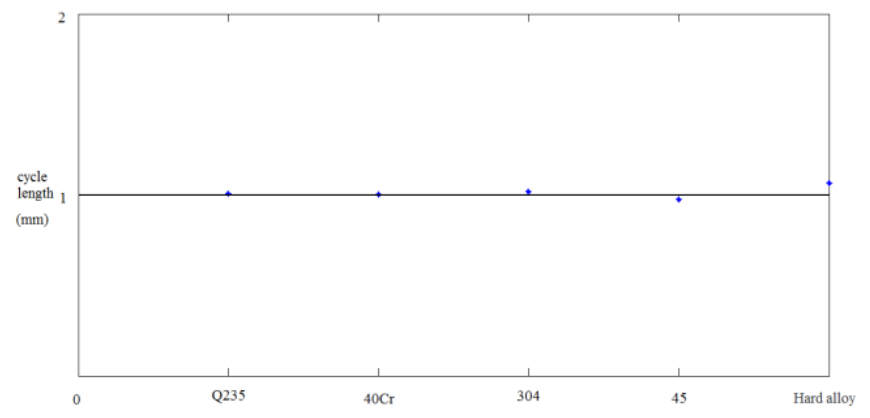

Fig. (10). Cycle length of scale veins under different parameters.

\subsection{Influence of Rotating Speed of Spindle and Feed Speed on Surface Roughness}

In the case of the same feed speed, rotating speed is higher, the feed distance of the tool tip within one cycle is smaller, and deformation is smaller. At the same time, the change in the extrusion force of the tool tip on the formed surface of the sheet metal is smaller, and surface roughness is smaller. On the contrary, surface roughness is larger.

When the rotating speed of spindle is regular, the feed speed is lower, the feed distance of the tool tip within one cycle is smaller, the deformation of the tool tip is smaller, change in the pressure on the formed surface is smaller, and surface roughness is smaller. On the contrary, surface roughness is larger.

\subsection{Influence of Tool Head Material on Surface Roughness}

From experimental data, surface roughness $\mathrm{Rz}$ is different with difference in the tool head materials in the case that the feed speed $\mathrm{F}$ is equal to the rotating speed $\mathrm{S}$ of spindle. The reason is that when the feed speed $\mathrm{F}$ is equal to the rotating speed $\mathrm{S}$ of spindle, force of the tool head is the same; and when the hardness of the tool head materials is smaller, deformation is larger, change in pressure on the formed surface is larger, the scale veins are more obvious, and surface roughness $\mathrm{Rz}$ is larger. When the hardness of the tool head materials is larger, deformation is smaller, change in pressure on the formed surface is smaller, the scale veins are more unapparent, and surface roughness $\mathrm{Rz}$ is smaller, as shown in the Fig. (11).

(a) The hardness of tool head material is high

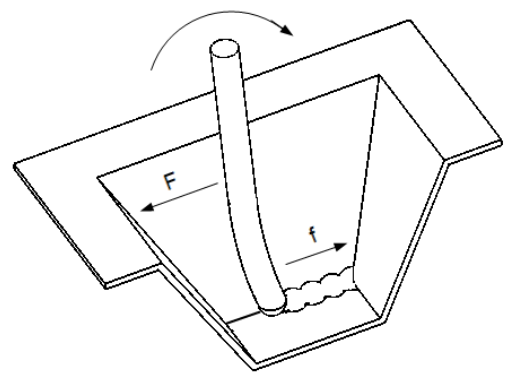

(b) The hardness of tool head material is low

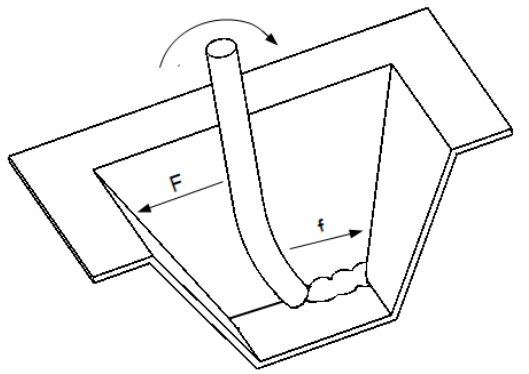

Fig. (11). Force analysis.

\section{CONCLUSION}

During the incremental forming of sheet metal, the formed surface may be subject to the periodically- 
changed pressure of size and orientation, thus, periodic veins may be formed under the pressure, namely scale veins.

(2) The cycle length of scale veins is in direct proportion to the feed speed, and is be inversely proportional to the rotating speed.

When the feed speed is regular, the rotating speed of spindle is lower, the scale veins are more obvious, surface roughness $\mathrm{Rz}$ is larger, and on the contrary, surface roughness $\mathrm{Rz}$ is smaller. When the rotating speed of spindle is regular, the feed speed is higher, the scale veins are more obvious, surface roughness $\mathrm{Rz}$ is larger, and on the contrary, surface roughness $\mathrm{Rz}$ is smaller.

(4) The hardness of tool head material is smaller, the scale veins are more obvious, surface roughness $\mathrm{Rz}$ is larger, and on the contrary, surface roughness $\mathrm{Rz}$ is smaller.

\section{CONFLICT OF INTEREST}

The authors confirm that this article content has no conflict of interest.

\section{ACKNOWLEDGEMENTS}

This work is supported by the National Natural Science Foundation of China (Grant No. 51475366, No. 50975229).

\section{REFERENCES}

[1] J. Mo, and F. Han, "State of the arts and latest research on incremental sheet NC forming technology", China Mechanical Engineering," vol. 19, no. 4, pp. 491-497, 2007.

[2] H. Zhu, J. Fu, and J. Kang, "Generation of spiral tool path for sheet metal CNC incremental forming", Transactions of the Chinese Society for Agricultural Machinery, vol. 40, no. 10, pp. 223-226, 2009.

[3] J. Liu, "Study on incremental forming principle of sheet metal", Journal of Hunan University of Technology, vol. 21, no. 3, pp. 52$55,2007$.

[4] M. Li, L. Zhang, and J. Mo, "Tool path generation method for single point incremental forming", Transactions of the Chinese Society for Agricultural Machinery, vol. 42, no. 3, pp. 225-228, 2011.

[5] H. Zhu, Z. Liu, and J. Fu, "Multi-stage CNC incremental forming path generation based on surface zoning," Transactions of the Chinese Society for Agricultural Machinery, vol. 41, no. 10, pp. 230-234, 2010.
[6] J. Mo, C. Ye, and S. Huang, "Sheet metal CNC incremental forming", Aeronautical Manufacturing Technology, no. 12, pp. 2527, 2002 .

[7] Z. Hu, M. Li, and Z. Sui, "Spinning technology based on principle of continuous multipoint forming", Transactions of the Chinese Society for Agricultural Machinery, vol. 40, no. 12, pp. 247-250, 2009.

[8] X. Chen, M. Li, and W. Fu, "Simulation on dynamic contact forces of punches in multi-point forming process", Transactions of the Chinese Society for Agricultural Machinery, vol. 41, no. 10, pp. 223-226, 2010.

[9] Y. Xu, S. He, and L. Gao, "Influencing factors of surface quality for complicated sheet parts by incremental forming method", Journal of Nanjing University of Aeronautics \& Astronautics, vol. 41, no. 5, pp. 559-563, 2009.

[10] K. Hamilton, and J. Jeswiet, "Single point incremental forming at high feed rates and rotational speeds: surface and structural consequences", CIRP Annals-Manufacturing Technology, vol. 59 no. 1, pp. 311-314, 2010.

[11] M. Durante, A. Formisano, and A. Langella, "Comparison between analytical and experimental roughness values of components created by incremental forming", Journal of Materials Processing Technology, vol. 210, no. 14, pp. 1934-1941, 2010.

[12] T. Schafer, and R. Schraft, "Incremental sheet metal forming by industrial robots", Rapid Prototyping Journal, vol. no. 11, pp. 278 286, 2005.

[13] S. J. Yoon, and D. Y. Yang, "An incremental roll forming process for manufacturing doubly curved sheets from general quadrilateral sheet blanks with enhanced process features", CIRP Annals Manufacturing Technology, no. 54, no. 1, pp. 221-224, 2005.

[14] J. Kopac, and Kampus Z, "Incremental sheet metal forming on CNC milling machine-tool," Journal of Materials Processing Technology, vol. 162, no. 163, pp. 622-628, 2005.

[15] J. M. Allwood G. King, and J. Duflou, "A structured search for applications of the incremental sheet-forming process by product segmentation", Proceedings of the Institution of Mechanical Engineers, Part B: Journal of Engineering Manufacture vol. 219, pp. 239-244, 2005.

[16] J. Zhou, S. Peng, and X. Zhang, "Effects of limited half-cone angle and interlayer spacing on quality of incremental sheet metal forming," Hot Working Technology, vol. 39, no. 9, pp. 34-36, 2010.

[17] J. Li, X. Zhang and S. Peng, "Experimental and numerical research on thickness variation of dieless sheet metal incremental forming", Hot Working Technology, vol. 40, no. 7, pp. 1-4, 2011.

[18] L. Tao, J. Wang, and H. Jiang, "Effect of process parameters on formability incremental forming", Forging \& Stamping Technology, vol. 37, no. 3, pp. 19-22, 2012.

[19] H. Jiang, and X. Li, "Study on single-point incremental forming limit based on orthogonal experiment design", Machinery Design \& Manufacture, vol. 11, pp. 215-216, 2010.

[20] X. Song, B. Lu, and J. Chen, "Influencing factor analysis on the surface quality of incremental forming parts", Journal of Mechanical Engineering, vol. 49, no. 8, pp. 84-89, 2013.

[21] H. Wen, X. Du, and P. Shi, "Comparative study on surface roughness between theoretical and experimental values in metal sheet incremental forming", Hot Working Technology, vol. 44, no. 3, pp. 130-134, 2015. 